\title{
Residual Pleural Thickening Is Related to Vascular Endothelial Growth Factor Levels in Parapneumonic Pleural Effusions
}

\author{
Andriana I. Papaioannou Konstantinos Kostikas Paschalina Tsopa \\ Theodoros Kiropoulos Irene Tsilioni Smaragda Oikonomidi Irene Gerogianni \\ Konstantinos I. Gourgoulianis \\ Department of Respiratory Medicine, University of Thessaly Medical School, Larissa, Greece
}

\section{Key Words}

Vascular endothelial growth factor $\cdot$ Residual pleural

thickening $\cdot$ Parapneumonic effusions

\begin{abstract}
Background: Many patients with pneumonia develop pleural effusions. Pleural fluid vascular endothelial growth factor (VEGF) levels are known to be elevated in complicated parapneumonic effusion and seem to play a major role in the fibrotic process in the pleura. Objectives: To test whether VEGF levels in pleural effusions of infectious origin correlate with the residual pleural thickening. Methods: VEGF levels were measured in the pleural fluid of 45 patients with pleural effusion of infectious origin. Patients were reassessed 3 months after hospital discharge and residual pleural thickening (RPT) was recorded using a simple chest radiograph. Results: Pleural fluid VEGF was higher in empyemas compared to simple parapneumonic and complicated parapneumonic effusions. RPT was higher in patients with empyemas compared to simple parapneumonic effusions. Patients with RPT $>2 \mathrm{~mm}$ had higher pleural fluid LDH and pleural fluid to serum $\mathrm{LDH}$ ratio, lower glucose and $\mathrm{pH}$ and higher VEGF levels. However, patients with RPT $\geq 10 \mathrm{~mm}$ differed only in pleural fluid VEGF levels. Pleural fluid VEGF levels correlated to RPT and to pleural fluid pH. VEGF presented
\end{abstract}

moderate performance for the prediction of RPT 3 months after hospital discharge. Its performance was comparable to that of pleural fluid glucose and $\mathrm{pH}$ for the development of a radiologically significant $\mathrm{RPT}>2 \mathrm{~mm}$, whereas it was the only statistically significant predictor of a clinically significant RPT $\geq 10 \mathrm{~mm}$. Conclusion: VEGF levels are elevated in complicated parapneumonic effusions and empyemas compared to simple parapneumonic effusions and are a significant predictor for the development of clinically significant RPT.

Copyright $\odot 2009$ S. Karger AG, Basel

\section{Introduction}

Approximately $57 \%$ of patients with pneumonia develop pleural effusion [1]. Pleural fluid can progressively evolve from a simple exudate (simple parapneumonic effusion) to a fibrinopurulent stage (complicated parapneumonic effusion) and later to frank pus (called empyema) [1]. Exudates related to pneumonia develop from fluid movement into the pleural cavity due to increased vascular permeability of the inflamed pleura accompanied by the production of proinflammatory cytokines $[2,3]$. Furthermore, exudates due to parapneumonic effusions and empyema demonstrate increased procoagu-

\section{KARGER}

Fax +41613061234 E-Mail karger@karger.ch www.karger.com (c) 2009 S. Karger AG, Basel

0025-7931/10/0806-0472\$26.00/0

Accessible online at: www.karger.com/res
Konstantinos Kostikas, MD, FCCP

Stamouli 3

GR-43100 Karditsa (Greece)

Tel. +30 694478 0616, Fax +30 244102 2370, E-Mail ktk@ otenet.gr 
lant and suppressed fibrinolytic activities, favoring fibrin deposition in the pleural space and proliferation of fibroblasts [2], which can cause characteristic changes in the pleural space, including loculations and pleural thickening [4].

Vascular endothelial growth factor (VEGF) is a cytokine which has a potent ability to induce vascular leakage and, hence, formation of pleural effusions [5]. In humans, VEGF levels were higher in exudates compared to transudates [6] and were additionally increased in empyemas compared to nonpurulent effusions [7]. Finally, a recent study has demonstrated that pleurodesis is inhibited by anti-VEGF antibodies [8], indicating that VEGF plays a major role in the formation of pleural fibrosis.

The aim of the present study was to assess VEGF levels in patients with pleural effusions of infectious origin and to test whether those levels correlate with residual pleural thickening. Finally, we tested whether VEGF levels can predict the formation of radiologically and clinically significant residual pleural thickening (RPT).

\section{Materials and Methods}

\section{Study Subjects}

Forty-five subjects (10 females) with pleural effusion of infectious origin, who were hospitalized in the Department of Respiratory Medicine of the University of Larissa between June 2005 and May 2007, were included in the study. All patients had pneumonia and underwent diagnostic fluid sampling with thoracentesis. Patients who underwent surgical drainage and/or suffered from intrapleural fibrinolysis were not included in the study. We also excluded patients with a history of previous pleural effusion of any origin, previous thoracic surgery for any reason or a history of tuberculosis. The study protocol was approved by the local ethics committee and all patients provided written informed consent.

\section{Diagnosis of Pleural Effusion}

Pleural fluid was obtained from all patients during the initial diagnostic thoracentesis, prior to any therapeutic intervention. The routine study of the pleural fluid included measurements of total number of cells, cell type, pleural fluid glucose, total protein, lactate dihydrogenase ( $\mathrm{LDH}$ ) and $\mathrm{pH}$ determined by a blood gas analyzer. For the needs of the study, $\mathrm{pH}$ was measured even when pleural fluid had the appearance of frank pus. No damage of the blood gas analyzer was recorded. Microbiological cultures and Gram stain were also performed. All patients had exudative pleural effusions according to the criteria of Light et al. [9], with a neutrophilic cell count. Effusions were classified into simple parapneumonic (usually clear fluid with $\mathrm{pH}>7.2$, $\mathrm{LDH}<1,000$ IU/l, glucose $>2.2 \mathrm{mmol} / \mathrm{l}$ and no organism on culture or Gram stain), complicated parapneumonic (pleural fluid clear or cloudy, $\mathrm{pH}<7.2, \mathrm{LDH}>1,000 \mathrm{IU} / \mathrm{l}$, glucose $<2.2 \mathrm{mmol} / \mathrm{l}$, and possibly positive Gram stain or culture), and empyemas (pleural fluid having the appearance of frank pus and possibly positive Gram stain or culture) according to the classification of the British Thoracic Society [1].

\section{VEGF Measurement}

Pleural fluid samples were collected from all patients during routine diagnostic fluid sampling. Pleural fluid samples were centrifuged at $1,500 \mathrm{~g}$ for $10 \mathrm{~min}$ at $4^{\circ} \mathrm{C}$ and pleural fluid was collected and frozen at $-70^{\circ} \mathrm{C}$ pending measurements. VEGF levels were assessed with a commercially available enzyme-immunosorbent assay (R\&D Systems, Minneapolis, Minn., USA), according to the manufacturer's protocol. The lower limit of detection for VEGF was $9 \mathrm{pg} / \mathrm{ml}$.

Assessment of Pleural Effusion Size

The radiologic size of the pleural effusion was defined at the time of diagnosis as: (1) small when the costophrenic angle was obliterated but the hemidiaphragm was not covered; (2) medium when it was larger than in (1) but occupied less than two thirds of the space between the mediastinum and chest wall at the height of the hilum, and (3) large when it was greater than medium [10].

\section{Assessment of RPT}

RPT was measured 3 months after hospital discharge as previously described [10]. Briefly, RPT was measured in the lower lateral hemithorax of a posteroanterior chest radiograph at the level of an imaginary line intersecting the diaphragmatic dome. Pleural thickness was measured in millimeters. Two levels of pleural thickness were used in order to classify patients by the presence or absence of significant RPT. First, RPT was defined as a pleural thickness $>2 \mathrm{~mm}$, a value that is generally considered as radiologically abnormal $[10,11]$. Analyses were repeated using RPT defined as a pleural thickness $\geq 10 \mathrm{~mm}$ because this level of thickness has been shown to be a more specific marker for the development of restrictive functional sequelae in patients with tuberculous effusions, compared to $2 \mathrm{~mm}[10,12]$. Measurements were performed independently by two observers (A.I.P. and P.T.) blinded to the other's results and the mean value was used for the statistical analysis.

\section{Statistical Analysis}

Normally distributed data are presented as mean \pm standard deviation, whereas skewed data are presented as median (interquartile ranges). The normality of the distribution was examined with the Kolmogorov-Smirnov test. Comparisons between groups were performed using one-way analysis of variance with Bonferroni post hoc tests for normally distributed data or Kruskal-Wallis test with Dunn's post-hoc tests for skewed data. Correlations were evaluated using Pearson's correlation coefficient for normally distributed variables or Spearman's rank correlation coefficient for skewed variables. For the assessment of predictors of RPT, receiver operating characteristics (ROC) curves were created and areas under the ROC curves with 95\% confidence intervals and their differences from 0.5 were calculated. Sensitivities, specificities, positive and negative predictive values were calculated for the optimal cut-off points of each ROC curve. Statistical analysis was performed with GraphPad Prism 5 (GraphPad Software Inc., La Jolla, Calif., USA) and MedCalc9 (MedCalc Software, Mariakerke, Belgium). A p value $<0.05$ was considered statistically significant. 

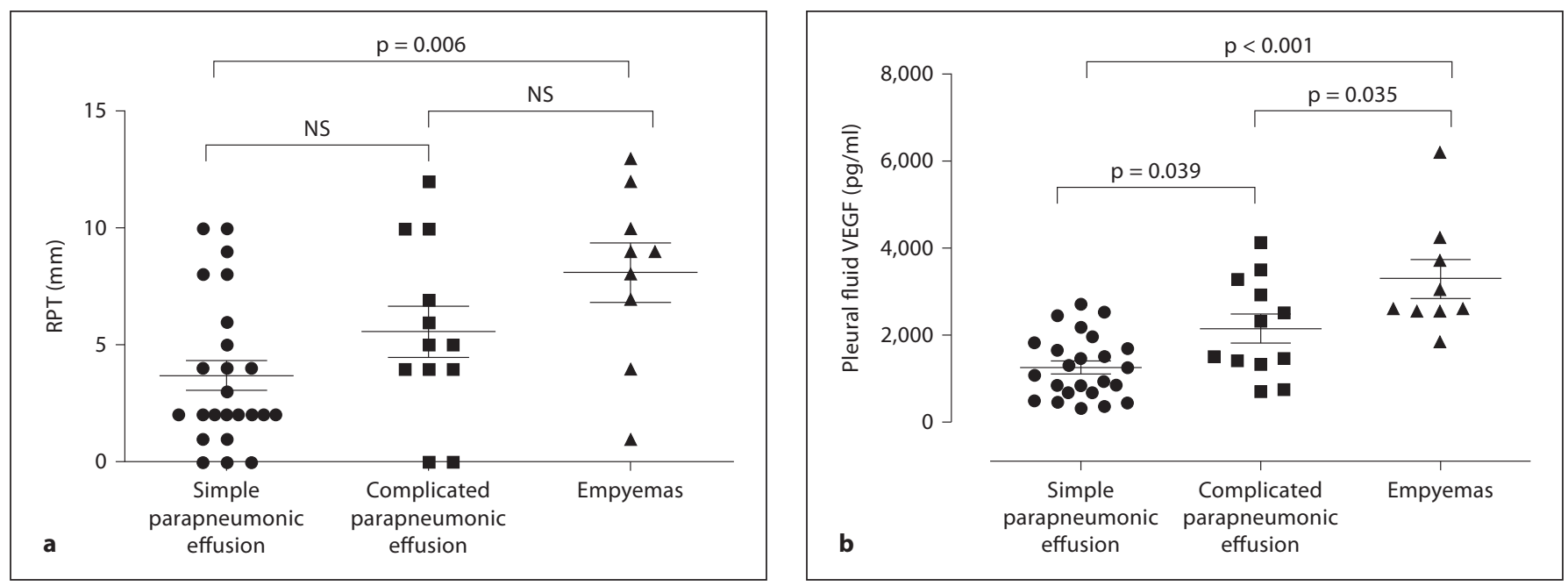

Fig. 1. RPT (a) and pleural fluid VEGF (b) levels in the different types of parapneumonic pleural effusions.

Table 1. Demographic and pleural fluid characteristics of the study participants

\begin{tabular}{|c|c|c|c|c|c|}
\hline & $\begin{array}{l}\text { All } \\
(n=45)\end{array}$ & $\begin{array}{l}\text { Simple } \\
\text { parapneumonic } \\
(\mathrm{n}=24)\end{array}$ & $\begin{array}{l}\text { Complicated } \\
\text { parapneumonic } \\
(\mathrm{n}=12)\end{array}$ & $\begin{array}{l}\text { Empyemas } \\
(\mathrm{n}=9)\end{array}$ & $\begin{array}{l}\mathrm{p} \\
\text { value }\end{array}$ \\
\hline Age & $53 \pm 17$ & $53 \pm 17$ & $51 \pm 19$ & $54 \pm 14$ & NS \\
\hline Gender, F/M & $10 / 35$ & $6 / 18$ & $2 / 10$ & $2 / 7$ & NS \\
\hline Total cells $/ \mu \mathrm{l}$ & $8,450(2,762,19,125)$ & $4,700(2,487,15,475)$ & $9,400(1,300,22,000)$ & $17,200(10,250,73,400)$ & NS \\
\hline Neutrophils, \% & $80(62,85)$ & $70(45,80)$ & $82(68.5,89.5)$ & $85(78.5-90.5)$ & 0.045 \\
\hline Neutrophils/ $\mu l$ & $4,750(2,221,22,093)$ & $4,200(2,405,11,852)$ & $2,861(538,28,794)$ & $22,176(9,503,103,800)$ & NS \\
\hline Lymphocytes, \% & $11(6.5,24)$ & $20(8.5,26)$ & $10(10,11.7)$ & $6(1,11)$ & 0.014 \\
\hline $\mathrm{pH}$ of pleural fluid & $7.16 \pm 0.30$ & $7.37 \pm 0.06$ & $6.93 \pm 0.28$ & $6.86 \pm 0.28$ & $<0.001$ \\
\hline Pleural fluid glucose, $\mathrm{mg} / \mathrm{dl}$ & $82.0(11.2,131)$ & $124(85.0,164)$ & $12.5(4.0,56)$ & $5(3.0,104)$ & $<0.001$ \\
\hline Pleural fluid LDH, U/1 & $1,156(446,2,667)$ & $508(282,1,070)$ & $1,942(1,339,3,555)$ & $6,350(1,751,17,392)$ & NS \\
\hline Pleural fluid LDH/serum ratio & $5.6(1.9,12,6)$ & $2.4(1.3,5.5)$ & $7.7(5.6,17.0)$ & $34.7(8.4,94.5)$ & 0.044 \\
\hline Pleural fluid protein, $\mathrm{mg} / \mathrm{dl}$ & $4.6(3.9,5.4)$ & $4.5(3.8,5.2)$ & $5.3(4.6,6.1)$ & $4.9(3.5,5.1)$ & NS \\
\hline Pleural fluid protein/serum ratio & $0.71(0.55,0.77)$ & $0.67(0.54,0.72)$ & $0.76(0.68,0.81)$ & $0.74(0.56,0.78)$ & NS \\
\hline Pleural fluid VEGF, pg/ml & $1,911 \pm 1,239$ & $1,268 \pm 728$ & $2,160 \pm 1,122$ & $3,293 \pm 1,308$ & $<0.001$ \\
\hline $\mathrm{RPT}, \mathrm{mm}$ & $5.0 \pm 3.7$ & $3.7 \pm 3.1$ & $5.5 \pm 3.7$ & $8.1 \pm 3.7$ & 0.007 \\
\hline
\end{tabular}

Values are given as the mean \pm SD or median (25th, 75th percentile) according to whether distribution is Gaussian or skewed, respectively, unless otherwise indicated.

\section{Results}

According to the British Thoracic Society criteria, 24 patients had simple parapneumonic effusions, 12 patients had complicated parapneumonic effusions, and 9 patients had empyemas. The characteristics of the study subjects according to their classification are presented in table 1.

RPT measured 3 months after hospital discharge was higher in empyemas compared to simple parapneumonic effusions ( $p=0.006$ ), whereas it did not differ significantly between simple and complicated parapneumonic effusions or between complicated parapneumonic effusions and empyemas. Pleural fluid VEGF was higher in empyemas compared to simple parapneumonic and complicated parapneumonic effusions $(\mathrm{p}<0.001$ and $\mathrm{p}=$ 0.035 , respectively); additionally, complicated parapneumonic effusions has higher VEGF levels compared to simple parapneumonic effusions $(p=0.039)$ (fig. $1 \mathrm{a}, \mathrm{b})$. 

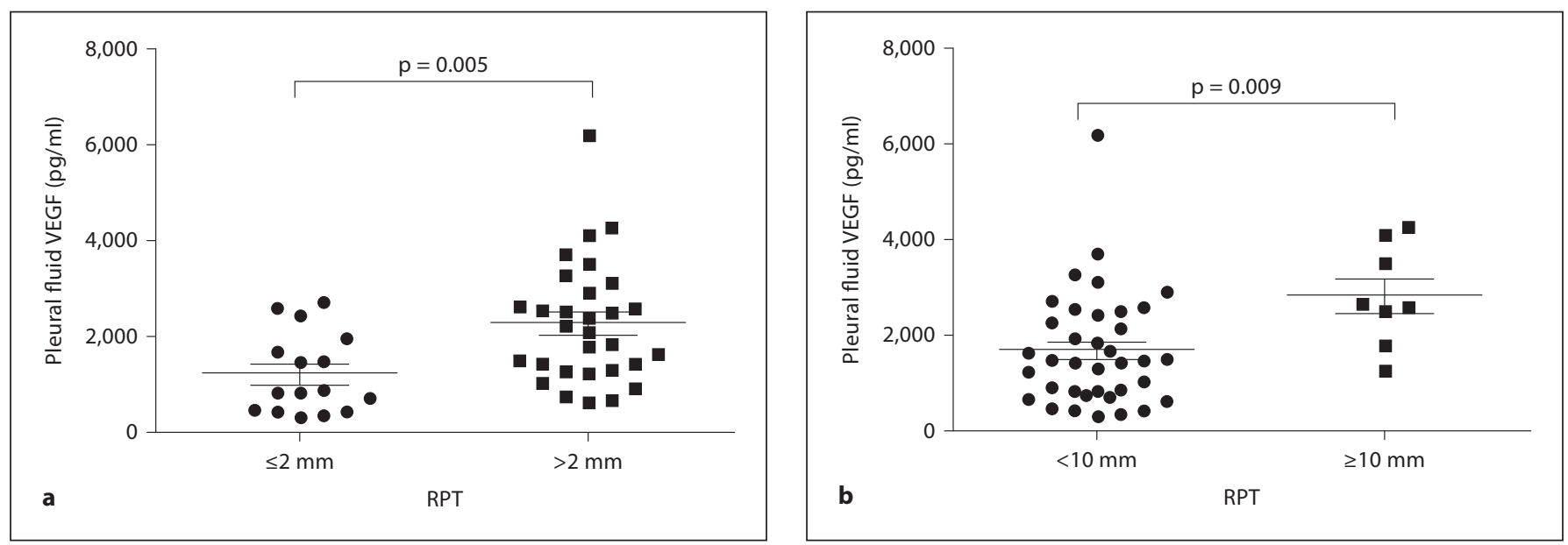

Fig. 2. VEGF levels in the pleural fluid of patients with RPT $\leq 2 \mathrm{~mm}$ and RPT $>2 \mathrm{~mm}$ (a) and with RPT $<10$ $\mathrm{mm}$ and $\mathrm{RPT} \geq 10 \mathrm{~mm}(\mathbf{b})$.

Table 2. Patient and pleural fluid characteristics for RPT $\leq 2 \mathrm{~mm}$ and RPTs $>2 \mathrm{~mm}$

\begin{tabular}{|c|c|c|c|}
\hline & $\mathrm{RPT} \leq 2 \mathrm{~mm}(\mathrm{n}=16)$ & $\mathrm{RPT}>2 \mathrm{~mm}(\mathrm{n}=29)$ & $\mathrm{p}$ value \\
\hline Age & $52(36,70)$ & $54(41,70)$ & NS \\
\hline Gender, M/F & $12 / 4$ & $23 / 6$ & \\
\hline $\mathrm{SP} / \mathrm{CP} / \mathrm{E}$ & $13 / 2 / 1$ & $11 / 10 / 8$ & \\
\hline 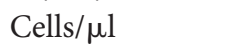 & $4,100(2,100,14,200)$ & $13,350(3,300,23,500)$ & NS \\
\hline Lymphocytes, \% & $14.5(7.7,26.0)$ & $10(6.0,20.0)$ & NS \\
\hline Neutrophils, $\%$ & $70.0(41.2,80.0)$ & $80.0(69.0,89.0)$ & NS \\
\hline Neutrophils/ $\mu \mathrm{l}$ & $2,840(1,241,10,837)$ & $8,580(3,395,43,420)$ & NS \\
\hline $\mathrm{pH}$ & $7.34 \pm 0.13$ & $7.06 \pm 0.33$ & 0.006 \\
\hline Glucose, mg/dl & $133(81,231)$ & $69(4,104)$ & 0.002 \\
\hline Protein, $g / 1$ & $4.18(3.82,5.02)$ & $5.1(4.2,5.6)$ & NS \\
\hline Protein ratio & $0.68(0.54,0.73)$ & $0.68(0.59,0.79)$ & NS \\
\hline $\mathrm{LDH}, \mathrm{U} / \mathrm{l}$ & $600(282,1,408)$ & $1,415(725,4,340)$ & 0.02 \\
\hline LDH ratio & $2.38(1.18,9.35)$ & $6.32(2.96,21.28)$ & 0.049 \\
\hline VEGF, pg/ml & $1,233 \pm 837$ & $2,165 \pm 1,277$ & 0.005 \\
\hline
\end{tabular}

Mean concentrations of biochemical components and markers of pleural fluid in patients distinguished by the presence or absence of RPT $>2 \mathrm{~mm}$. Values are given as the mean $\pm \mathrm{SD}$ or median (25th, 75 th percentile) according to whether the distribution is Gaussian or skewed, respectively, unless otherwise indicated. $\mathrm{SP}=$ Simple parapneumonic; $\mathrm{CP}=$ complicated parapneumonic; $\mathrm{E}=$ empyemas.

However, VEGF levels in the pleural fluid did not differ between patients with small, medium or large effusions (data not shown).

\section{Classification of Patients According to RPT}

Twenty-nine patients had RPT $>2 \mathrm{~mm}$ and 8 patients had RPT $\geq 10 \mathrm{~mm}$. The characteristics of the pleural fluid of these patients are shown in tables 2 and 3. As shown in table 2, patients with RPT $>2 \mathrm{~mm}$ had higher pleural fluid $\mathrm{LDH}$ and pleural fluid to serum $\mathrm{LDH}$ ratios, lower glucose and $\mathrm{pH}$ and higher VEGF levels. However, patients with RPT $\geq 10 \mathrm{~mm}$ differed only in pleural fluid VEGF levels (table 3). The differences in VEGF levels according to pleural thickening classification are presented in figure $2 a, b$. 

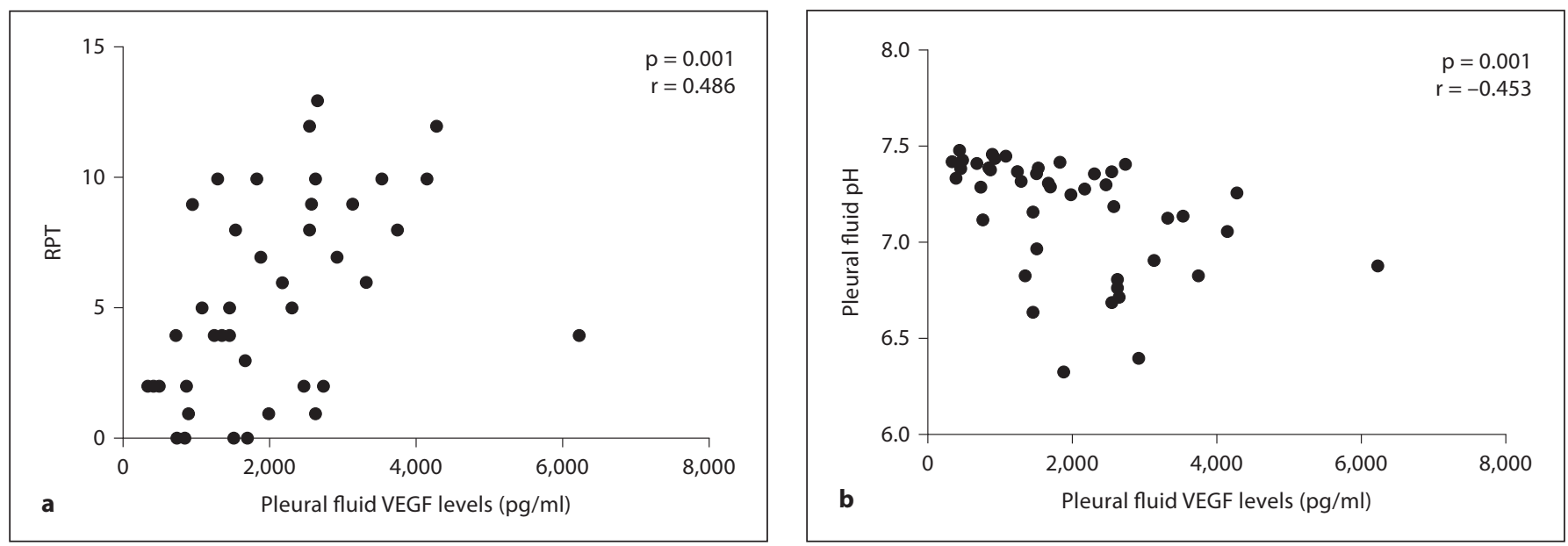

Fig. 3. Correlation of VEGF levels with RPT (a) and pleural fluid pH (b).

Table 3. Patient and pleural fluid characteristics for RPTs $<10 \mathrm{~mm}$ and RPT $\geq 10 \mathrm{~mm}$

\begin{tabular}{|c|c|c|c|}
\hline & $\mathrm{RPT}<10 \mathrm{~mm}(\mathrm{n}=37)$ & $\mathrm{RPT} \geq 10 \mathrm{~mm}(\mathrm{n}=8)$ & $\mathrm{p}$ value \\
\hline Age & $53(42,70)$ & $52(35,61)$ & NS \\
\hline Gender, M/F & $28 / 9$ & $7 / 1$ & \\
\hline $\mathrm{SP} / \mathrm{CP} / \mathrm{E}$ & $22 / 9 / 6$ & $2 / 3 / 3$ & \\
\hline 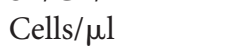 & $7,600(2,775,17,600)$ & $17,900(1,850,44,800)$ & NS \\
\hline Lymphocytes, \% & $11.0(6.0,24.0)$ & $11.0(7.7,21.7)$ & NS \\
\hline Neutrophils, \% & $80.0(60.0,85.0)$ & $80.0(62.0,87.0)$ & NS \\
\hline Neutrophils/ $\mu \mathrm{l}$ & $4,464(2,775,17,600)$ & $12,166(4,636,47,280)$ & NS \\
\hline $\mathrm{pH}$ & $7.18 \pm 0.30$ & $7.05 \pm 0.28$ & NS \\
\hline Glucose, mg/dl & $84(5,143)$ & $78(42,106)$ & NS \\
\hline Protein, $\mathrm{g} / \mathrm{l}^{\circ}$ & $4.6(5.0,143.3)$ & $5.1(4.7,5.8)$ & NS \\
\hline Protein ratio & $0.72(0.54,0.74)$ & $0.78(0.60,0.97)$ & NS \\
\hline $\mathrm{LDH}, \mathrm{U} / \mathrm{l}$ & $1,156(409,2,544)$ & $1,503(740,6,892)$ & NS \\
\hline LDH ratio & $6.26(1.68,11.82)$ & $3.42(2.13,34.12)$ & NS \\
\hline VEGF, pg/ml & $1,708 \pm 1,192$ & $2,851 \pm 1,056$ & 0.007 \\
\hline
\end{tabular}

Mean concentrations of pleural fluid biochemical components and markers in patients separated by presence or absence of RPT $\geq 10 \mathrm{~mm}$. Values are given as the mean $\pm \mathrm{SD}$ or median (25th, 75 th percentile) according to whether the distribution is Gaussian or skewed, respectively, unless otherwise indicated.

$\mathrm{SP}=$ Simple parapneumonic $; \mathrm{CP}=$ complicated parapneumonic $\mathrm{E}=$ empyemas.

\section{Correlations of VEGF Levels}

There was a significant positive correlation between pleural fluid VEGF levels and RPT measured 3 months after hospital discharge ( $\mathrm{p}=0.001, \mathrm{r}=0.486$; fig. $3 \mathrm{a})$. There was a significant negative correlation between pleural fluid VEGF levels and the levels of pleural fluid $\mathrm{pH}(\mathrm{p}=0.001, \mathrm{r}=-0.453$; fig. $3 \mathrm{~b})$.
ROC Analysis for the Evaluation of Predictors of RPT at Baseline

ROC curves were created to evaluate the predictive performance of different characteristics of pleural fluid characteristics at the initial thoracentesis in the development of RPT at 3 months after hospital discharge. ROC analyses were performed both for RPT $>2 \mathrm{~mm}$ and $\geq 10$ $\mathrm{mm}$ and are shown in tables 4 and 5 , respectively. VEGF 
Table 4. ROC analysis for the evaluation of pleural fluid biomarkers at the time of diagnosis for the subsequent development of RPT $>2 \mathrm{~mm}$

\begin{tabular}{|c|c|c|c|c|c|c|c|}
\hline & Cut-off point & Sensitivity & Specificity & PPV & NPV & AUC & $\mathrm{p}$ value \\
\hline Pleural fluid glucose & $\leq 108 \mathrm{mg} / \mathrm{dl}$ & $0.79(0.60-0.92)$ & $0.67(0.38-0.88)$ & 0.82 & 0.62 & $0.792(0.643-0.899)$ & 0.0002 \\
\hline Pleural fluid LDH & $>1,790 \mathrm{U} / 1$ & $0.48(0.29-0.67)$ & $0.94(0.69-0.99)$ & 0.93 & 0.50 & $0.711(0.557-0.836)$ & 0.0063 \\
\hline \multicolumn{8}{|l|}{ Pleural fluid LDH/ } \\
\hline serum ratio & $>2.06$ & $0.86(0.68-0.96)$ & $0.50(0.25-0.75)$ & 0.76 & 0.67 & $0.679(0.520-0.810)$ & 0.0267 \\
\hline Pleural fluid pH & $\leq 7.28$ & $0.65(0.44-0.83)$ & $0.86(0.57-0.98)$ & 0.89 & 0.57 & $0.765(0.605-0.884)$ & 0.0016 \\
\hline Pleural fluid VEGF & $>873 \mathrm{pg} / \mathrm{ml}$ & $0.89(0.73-0.98)$ & $0.56(0.29-0.80)$ & 0.80 & 0.75 & $0.756(0.606-0.872)$ & 0.0003 \\
\hline
\end{tabular}

Figures in parentheses are 95\% CI. PPV = Positive predictive value; NPV = negative predictive value.

Table 5. ROC analysis for the evaluation of pleural fluid biomarkers at the time of diagnosis for the subsequent development of RPT $\geq 10 \mathrm{~mm}$

\begin{tabular}{llllllll}
\hline & Cut-off point & Sensitivity & Specificity & PPV & NPV & AUC & p value \\
\hline Pleural fluid glucose & $\leq 124 \mathrm{mg} / \mathrm{dl}$ & $1.00(0.63-1.00)$ & $0.33(0.18-0.51)$ & 0.25 & 1.00 & $0.528(0.372-0.680)$ & 0.805 \\
Pleural fluid LDH & $>649 \mathrm{U} / \mathrm{l}$ & $0.87(0.48-0.98)$ & $0.38(0.22-0.55)$ & 0.23 & 0.93 & $0.588(0.431-0.732)$ & 0.448 \\
Pleural fluid LDH/ & & & & & & & \\
$\quad$ & & & & & & \\
$\quad$ serum ratio & $\leq 3.8$ & $0.62(0.25-0.91)$ & $0.62(0.45-0.77)$ & 0.26 & 0.88 & $0.503(0.351-0.656)$ & 0.976 \\
Pleural fluid pH & $\leq 7.26$ & $0.75(0.35-0.96)$ & $0.62(0.44-0.79)$ & 0.33 & 0.91 & $0.682(0.516-0.820)$ & 0.637 \\
Pleural fluid VEGF & $>2,524 \mathrm{pg} / \mathrm{ml}$ & $0.75(0.35-0.96)$ & $0.78(0.62-0.88)$ & 0.43 & 0.94 & $0.797(0.651-0.902)$ & 0.002
\end{tabular}

Figures in parentheses are 95\% CI. PPV = Positive predictive value; NPV = negative predictive value.

performed moderately in both cases, as expressed by the corresponding areas under the ROC curves. Its performance was comparable to that of pleural fluid glucose and $\mathrm{pH}$ for the development of a radiologically significant RPT $>2 \mathrm{~mm}$ whereas it was the only statistically significant predictor of a clinically significant $\mathrm{RPT} \geq 10$ $\mathrm{mm}$ (fig. 4a, b, respectively).

\section{Discussion}

In the present study, we have shown that VEGF levels in the pleural fluid of patients with effusions of infectious origin were higher in empyemas compared to simple or complicated parapneumonic effusions. Pleural fluid VEGF levels were additionally higher in patients who presented with RPT $>2 \mathrm{~mm}$ and in those with RPT $\geq 10$ $\mathrm{mm}$ at 3 months after hospital discharge. A significant positive correlation of pleural fluid VEGF levels with RPT was observed, along with a negative correlation with pleural fluid $\mathrm{pH}$. Finally, a significant novel finding of the present study is that VEGF was the only factor in the pleural fluid that could predict the development of RPT $\geq 10 \mathrm{~mm}$.

It has already been reported that VEGF levels are higher in empyemas compared to simple parapneumonic effusions $[7,13]$, and our results are in agreement with those findings. It is known that when empyemas are left untreated, fibrinous loculations develop and progressively organize into fibrotic tissue [7]. VEGF is known to play an important role in this process by making endothelial cells hyperpermeable to fibrinogen within the extravascular space, leading to the formation of a fibrin gel [14]. The aforementioned findings could possibly lead to the conclusion that the greater RPT that occurs in empyemas and complicated parapneumonic effusions compared to simple parapneumonic effusions might be, at least in part, related to the elevated VEGF levels in the pleural fluid.

Several parameters in the pleural fluid, such as $\mathrm{pH}$, $\mathrm{LDH}$ and glucose levels, have been shown to be associated with the development of RPT [4]. In our study, we 

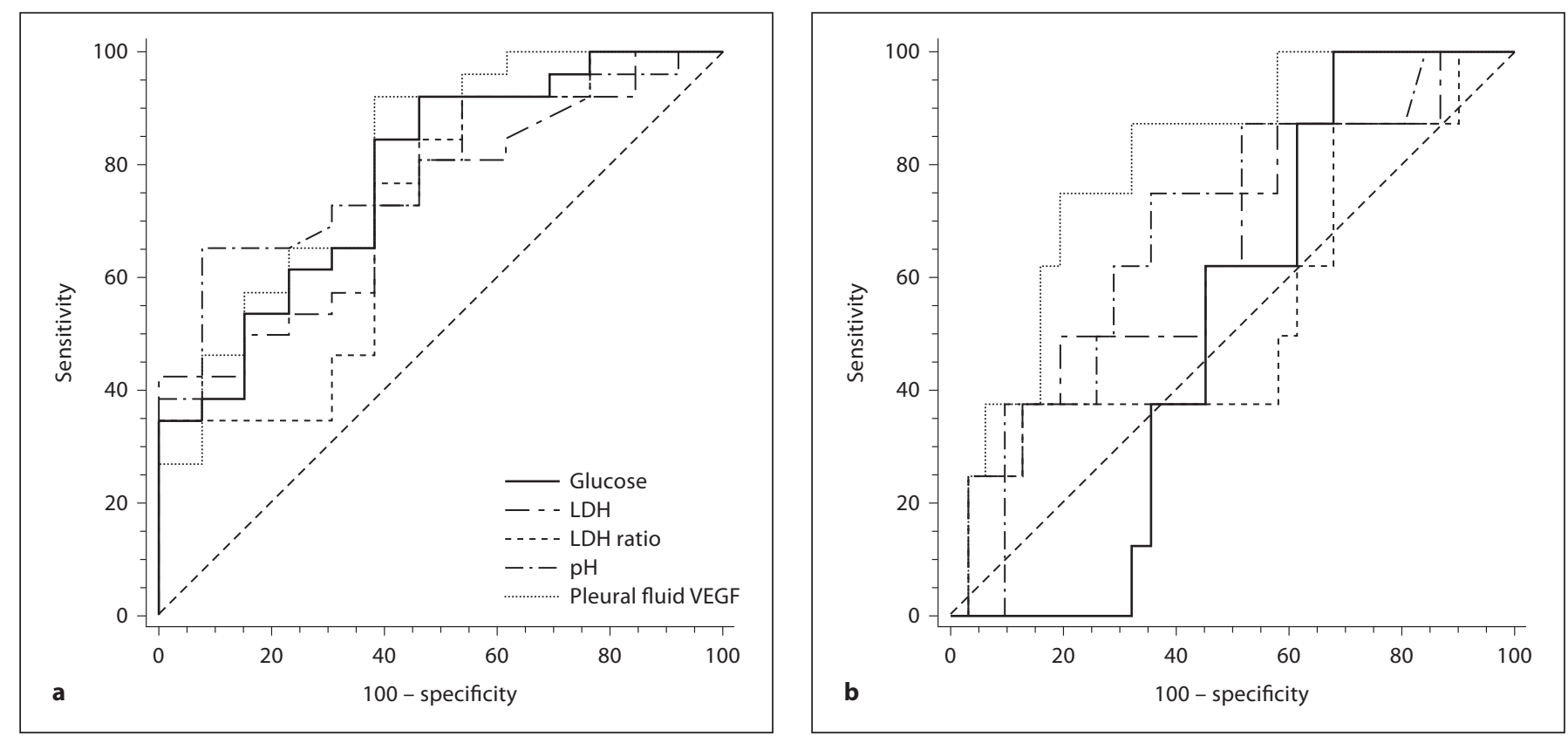

Fig. 4. ROC curves for the evaluation of the predictive performance of different markers of the pleural fluid in the development of radiologically significant RPT $(>2 \mathrm{~mm})(\mathbf{a})$ and clinically significant RPT $(\geq 10 \mathrm{~mm})$ at 3 months after hospital discharge (b).

have shown, using ROC analysis, that although several characteristics in the pleural fluid are associated with the development of radiographically abnormal RPT (i.e. $>2$ $\mathrm{mm}$ ), VEGF was the only pleural fluid parameter that could predict the development of RPT, which may have important clinical implications. Transforming growth factor- $\beta$ (TGF- $\beta$ ), a cytokine that is elevated in empyemas as well [15], further induces VEGF production from endothelial cells [5]. It has been shown that VEGF levels in the pleural fluid correlate with TGF- $\beta$ levels [16]. Knowing that TGF- $\beta$ can be very effective in inducing pleurodesis $[17,18]$, one can hypothesize that the correlation of pleural fluid VEGF levels with RPT may also be mediated by TGF- $\beta$.

A correlation of pleural fluid VEGF levels with pleural fluid $\mathrm{pH}$ in exudative pleural effusions has also been shown recently [13], a finding that was replicated in parapneumonic effusions in our study. $\mathrm{pH}$ is a major factor for the differentiation of parapneumonic pleural effusions into simple and complicated parapneumonic effusions [1], and has also been shown to have the highest diagnostic accuracy for identifying complicated parapneumonic pleural effusions [19]. Furthermore, pleural fluid $\mathrm{pH}$ has been shown to be an independent factor associated with residual pleural thickening in parapneu- monic effusions [4]. In a recent study, it has been shown that acidification increased VEGF production in rat retinal extracts; this process was reversed by the use of antioxidants [20]. A similar mechanism may be related to the development of RPT, involving pleural acidification and VEGF production. To our knowledge, there are no studies describing the effects of pleural acidification in cytokine production from mesothelial cells, and this could be an interesting field for further research.

Recent studies have shown that the fibrotic process in the pleura can be interrupted by anti-VEGF antibodies [8]. Having in mind the aforementioned information, our findings, showing that pleural fluid VEGF levels are a significant predictor for the development of clinically significant RPT, may provide evidence supporting that antiVEGF antibodies may be effective anti-fibrotic agents in parapneumonic effusions. Our data further suggest that possible candidates for antifibrotic management might be patients with VEGF pleural fluid levels $>2,524 \mathrm{pg} / \mathrm{ml}$ at the initial diagnostic thoracentesis, thus providing evidence for the necessity of early intervention in those patients in order to prevent the development of clinically significant RPT. However, despite recent studies showing that the fibrotic process can be interrupted by anti-VEGF antibodies, at present cut-off levels of VEGF to facilitate 
the administration of antibodies and randomized human trials are lacking.

In conclusion, in the present study we have shown that VEGF levels are elevated in complicated parapneumonic effusions and empyemas compared to simple parapneumonic effusions and are associated with the development of RPT. Our data further support evidence suggesting that VEGF is an important factor in the fibrotic process in parapneumonic effusions. Finally, we have shown that pleural fluid VEGF levels in diagnostic thoracentesis may predict the development of RPT. Anti-VEGF antibodies which are available nowadays may provide a novel approach to the future management of parapneumonic effusions.

\section{References}

1 Davies CW, Gleeson FV, Davies RJ: BTS guidelines for the management of pleural infection. Thorax 2003;58(suppl 2):ii18-ii28.

2 Kroegel C, Antony VB: Immunobiology of pleural inflammation: potential implications for pathogenesis, diagnosis and therapy. Eur Respir J 1997; 10:2411-2418.

-3 Jantz MA, Antony VB: Pathophysiology of the pleura. Respiration 2008;75:121-133.

-4 Jimenez Castro D, Diaz G, Perez-Rodriguez E, Light RW: Prognostic features of residual pleural thickening in parapneumonic pleural effusions. Eur Respir J 2003;21:952-955.

5 Gary Lee YC, Melkerneker D, Thompson PJ, Light RW, Lane KB: Transforming growth factor $\beta$ induces vascular endothelial growth factor elaboration from pleural mesothelial cells in vivo and in vitro. Am J Respir Crit Care Med 2002;165:88-94.

6 Sack U, Hoffmann M, Zhao XJ, Chan KS, Hui DS, Gosse H, Engelmann L, Schauer J, Emmrich F, Hoheisel G: Vascular endothelial growth factor in pleural effusions of different origin. Eur Respir J 2005;25:600604.

7 Thickett DR, Armstrong L, Millar AB: Vascular endothelial growth factor (VEGF) in inflammatory and malignant pleural effusions. Thorax 1999;54:707-710.
8 Guo YB, Kalomenidis I, Hawthorne M, Parman KS, Lane KB, Light RW: Pleurodesis is inhibited by anti-vascular endothelial growth factor antibody. Chest 2005;128: 1790-1797.

-9 Light RW, Macgregor MI, Luchsinger PC, Ball WC Jr: Pleural effusions: The diagnostic separation of transudates and exudates. Ann Intern Med 1972;77:507-513.

10 de Pablo A, Villena V, Echave-Sustaeta J, Encuentra AL: Are pleural fluid parameters related to the development of residual pleural thickening in tuberculosis? Chest 1997;112: 1293-1297.

11 Light RW (ed): Pleural Disease, ed 3. Baltimore, Williams \& Wilkins, 1990.

12 Candela A, Andujar J, Hernandez L, Martin C, Barroso E, Arriero JM, Romero S: Functional sequelae of tuberculous pleurisy in patients correctly treated. Chest 2003;123: 1996-2000.

13 Ruiz E, Aleman C, Alegre J, Monasterio J, Segura RM, Armadans L, Vazquez A, Soriano T, Fernandez de Sevilla T: Angiogenic factors and angiogenesis inhibitors in exudative pleural effusions. Lung 2005;183:185-195.

14 Nehls V, Herrmann R: The configuration of fibrin clots determines capillary morphogenesis and endothelial cell migration. Microvasc Res 1996;51:347-364.

15 Charan NB, Baile EM, Pare PD: Bronchial vascular congestion and angiogenesis. Eur Respir J 1997;10:1173-1180.
16 Cheng D, Lee YC, Rogers JT, Perkett EA, Moyers JP, Rodriguez RM, Light RW: Vascular endothelial growth factor level correlates with transforming growth factor- $\beta$ isoform levels in pleural effusions. Chest 2000;118: 1747-1753.

17 Light RW, Cheng DS, Lee YC, Rogers J, Davidson J, Lane KB: A single intrapleural injection of transforming growth factor- $\beta_{2}$ produces an excellent pleurodesis in rabbits. Am J Respir Crit Care Med 2000;162:98104.

18 Gary Lee YC, Teixeira LR, Devin CJ, Vaz MA, Vargas FS, Thompson PJ, Lane KB, Light RW: Transforming growth factor- $\beta_{2}$ induces pleurodesis significantly faster than talc. Am J Respir Crit Care Med 2001;163: 640-644.

19 Jimenez Castro D, Diaz Nuevo G, Sueiro A, Muriel A, Perez-Rodriguez E, Light RW: Pleural fluid parameters identifying complicated parapneumonic effusions. Respiration 2005;72:357-364.

20 Zhu D, Xu X, Zheng Z, Gu Q: Regulation of vascular endothelial growth factor and pigment epithelium-derived factor in rat retinal explants under retinal acidification. Eye (Lond) 2009, Epub ahead of print. 